\title{
Teoria do Departamento de Administração Geral
}

\author{
Cruso M. Funtado \\ Teichico de Adminarraglo do D,S,F. \\ do Esf. do Rivo
}

\begin{abstract}
O surter no presente trabalho focallisa in evolugats

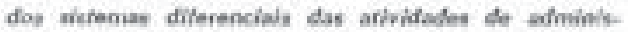

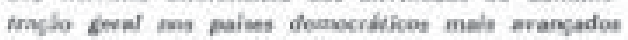
e termina por sifuar o D.A.S.P. e a reforma aefini-

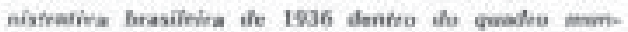
diel de progresso ciestitite yure rem Rastreacio a moterna edminiafrayĭn publice. (N.R.)
\end{abstract}

\section{A REVOLUÇKO POLTTICA}

A 5 grandes mutaçóts trazidies ì estrutura social, nos âtimes cem anos, pela transformaçło đas técnicas de produçăo, assumiram dois aspectos que nos interessa salientar s um politico e outro técnico.

A revolucso politica caracterizou-se pela valorizaçăo de um número crescente de grupos socinis. Pode ser chamada de democratizaça fundamental progressiva. Já foi denominada de rebelillo das masseas.

A valoriraçāo do homem comum traxida pela revoluça ino instrial tranaformou cabalmente a evtrutura politics, criando uma nova constelaçlo de valores em torno de velhas instituipóes. 0 poder politico que fồra, anteriormente, um patrimổnio inalienaivel de determinada classe constitusida de grupos socieis estírveis e detentora exclusiva de certas técnicas de mando, passoca a ser disputado por erupos proverientes de camadas cads vez mais amplas da sociedade.

Essa valarizaçlo de novos grupos sociais nila foi acompanhada, entretanto, de um processo educativo que os equiparasse, em experiéncia e consetència cultural à velhas elites (1). Entre an consequências dêsse desnivelamento de grupos so-

(1) Para wana interpretagde semelhante veja-se Marold


Tiempo, pliz, 17, Trodoplo ergentina. ciais, têta constituide objetos de análise o fmpeto revolucionário e o adormecimento contra-revolucionlírio - aspectos da "democracia de emoçöes" a que se refere Max Scheler.

Interessa-nos assinalar que ésse entrechoque de urupos sociais concorrentes ao poder, tornou profundamente dinamica a arena politica, emprestando no Estado uma nova importäncia como instrumento de moderaç̇o entre farças antagônicas.

\section{A RACIONALIZAÇAO}

Outra consequèencia na estruturaçăo social da fevolução das téenicas de produçiáa, fol o desenvelvimento crescente do processo de competiçắo. Tem-ae observado os reflexos do hipertrofiameato désse processo em quase tôdas as instituigobes sociais e na deformaçlio da personalidade bumana. O que nos preocupa, entretanto, é frizar que essa multiplicaçăo das formas de competiçōo constituiu a mola de inuimeros aperfeiçoamentos nas têcnicss de trabalho, e representou o ponto de partida de um novo nócleo de estudos. A necessidade de vencer a concorrência engendraria tóda uma serie de aperfeiçoamentos nos processos de trabaltso e na composiçño das emprêtsas.

Estes estudos, que representaram desde o início uma forma de análise social, levaram à identificaçẫo de um novo instrumento de papel catalitico nas reaçoóes de que saio agentes os fatóres da produçïo - a organizaçăo. Chegotu-se axsim à identificaçân de "principios extraidos indutivamente do estudo da experiência bumana, principios que podem condicionar a compasiçía de tỉda e qualquer associaglio de bocneas" (2). Daquela "ati-

(2) L. Urwick, Orzanization as - Techniesal Problam, in Prpors an the Seiesces of Adininiztration, New Yerk. 1937, pie. 49. 
tude cientifica em face do trabatho" que Taylor defendeu cono sendo a essència do "seientific managemeat", (3) resultaria de um corpo de conhecimentos de valor universal na análise e na comportiçio dos grupamentos humanos.

\section{A REPERCUSSĀO NA ADMINISTRACৃAO POBLICA}

Foi no momento em que a Estado - debatendo-te enire suns novas e complexas funçốes $e$ uma velha instrumentalidade - lançou mấo dèsse cerpo de conhecimentos elaborado pelos pesquiadores das industrias privadas, que teve inicio a reformas ds acaunistracăo publica.

A revolcçáo paliticn impuzera aca governca a necessidade de una atitude dinàmica, de um prosrome sistemático de açio. A reforma da administraçto publica teria inicio, consequïentemente, nibo al anilase do trabstho o do grupamento das tarefas, como ocorreu ha indústria privada, mas na transformaça das cípolas, aa remolelaçầ dos apsrelhamentos diretores. Ocorria, assim, no campo sovernamental, uma inoculaçāo de idéias, uma aceitaçâo de técnicas elaboradas fora - um procesco endógeno de renovação.

Pode-se percelver ésse sentido de transformaçāo de cúpolas thas primeiras reformas realizadas, no fluxo das novas idétas, nos Estades Unides. A primeira comissāo oficial de plasejamento, de que hâ note, foi criadn, em Hartiard, Connecticut, em 1907 (5), Foì ainda nesse mesmo ano que iniciou suas ativilades, ma cidade de Nova York, o Burcau of Municipal Research. (6) Euse movi-

(3) F, W. Trylor, The principies et Solentilie Mansgrment, 191t, n. 130.

(4) A ricicnaliacion cou revulta do precesso de ebecorracheia, está na própria natwens das novas técnicas de

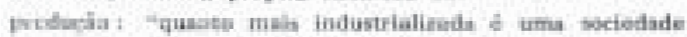

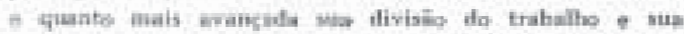
areanlascio maier seri e rimaro das enferas da atividade hemens que veriap funcianalmenie racignais, i por cumberiste, tambeim priviamente calculáveis, , A forge que cria em nessa sociedade as wirias formas de racionatidade brats ds industrialiraçìs cums uma fürç enpecifiea de ceganisaçus wocial. Keill Mannheim, Libertad y Planidicaciuin Social, jeisx. 54.56. Traducilg dn Fando de Cul. tura Econbetrica, Méaicos.

(5) Local Planvind Aolmindatration. Instatute fac Trainning in Municipal Administration, 1941, pie. 12 .

(6) Sehuyler Wellices, Federaf Departamendedisation. 1041 , pie. 13 . mento em nivel municipal seria seguido, de perto, de agitoş̌o näo menos fecunda em niveis estadual - legeral, A People's Power League of Oregon clabera, em 1909, uma proposta de plano de reorganizaçūo para o govírno e a administraçio daquele Estado, pela qual o poder executivo seria concentrado nas mẩos de um governaclor (7). Um ano depois surgiria a President's Commission on Economy and Efficiency, que de tä̀o fecundlas consequièncias seria para divulgação dos estudos de administraçào pública.

O corolário natural de uma política dinúmica seria, destarte, a formulação de plano para a açẫo administrativa, o qual passou a ser considerado "o đever do govèrno como agente do povo" (8).

Referindore as trabalhos dequeles pioneiros, que foram os batalhailores do citado Bureau of Municipal Research, dir Schuyler Wallace: "muito cido êles insistinam em que o conceito búsico da gervècla industrial, o planejamento, fósê colocado no centro do pensamento e da prática de soveirno". (9)

A idéta de que a formulaçáa do plano de açio, renovado este sempre num processo continuo era essencial para que a politich acompanhasae as mutaçbes sociats, corroborava com o principio técnico de que a administração para ser montada como um todo orghnice deveria vikar objetivos definsiles.

\section{ANALISE DA CHEFIA EXECUTIVA}

o primeiro groblema que se apresentou wos re. fermadores das administraçóes americanas foi 0 funcianamento do chefia executiva, A unidade de ação. essencial à execuçầ do plano de trabaltho, implicava na existència de uma chefia, centro coordenader e progulsar da máquina administrativa. "Serin fatal à eficiencia de um govertno entregar totalmente às agências separadas as probtemas de planejamento e execução. Os plancs devem ser coordenados e ajustades por alzum indt, viduo competente. A conclusalo inevitavel é que

(7) A. F. Buck. The Reoresuizatian of State Cioveramenta in the United States, 1938, ping. 6.

(8) Losal Flannina Aufminiatration, eit-, piest 15.

(9) Ob cit, pole 14 
deve haver um administredor chefe competente e tècaicamente treinado" (10).

A importuncia de tuma chefia centratixnda teve de ser defendida nos Estados Unidos contra umu tradiçŭe de admin straçăo local fragmentada. Tècnicamente, porkim, bsse problema nio pode ser formulado. Desde o momento que se reconbeça

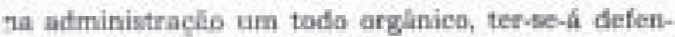
dido a existéncia de um centro coordenadar que será a chefia. $O$ que assoberbou o estudioso dessa matéria foi o problema do funcionameato da chefin. Já Taylor e Fayol meditaram sỏbre a ma. tèrià :

Com a feseavolvimento da indústria, ne sentido da camplexidade, e da açăo governimentat. no sentido da variedade, tornouse tho complexa a função de chefia que se cbegou a pensar na inpossibilidade de enfeixá-la nas māos de um só bomem

A soluchás de Taylor de divisio funcional da: chefias de oficina $n$ a supestake de Fayol no sentido de criagiano de um estado major so lado do chefe, constituem as duas contribuiçốes mais substenciosas para o esclarecimento do problema.

A enumeraçio das atribuições do chefe executivo aล adnainistraçüo páblica, feita pela Prof. L. D. Whites đak uma idéria do vulto da matéria t a) de terminar as linhas bísicas di politica administra tiva: b) emitir as neceasdrias ordens, instrucōes e comandos; c) coondenar a organizaçỉo; d) autorizar os detalbes da organizaglio; e) controlar " administração financeira; $f$ ) nomear e demitir o pessoal; d) supervisionar, facilitar e controlar as opxrapôes administrativas; $h$ ) investigar (11).

Reccabeceurse muito cedo a pecessidade de aparelhamento das chefias. O vulto e a complexidade de suas atribuiçbea impunha notỏriamente a criaçẫo los instrumentas que posabilitassem ao chefe o exercicio de sua funçăo. Era preciso definir que espécie de assisténcia podta ser prestada ao cheie, que funçôes suas podiam ser delegaLas, que posiçīo teriam de assumir tases delegados vm face das agências executoras.

En 1937, o President's Committee on Administrative Management refletiu ésse estágio do

(10) Hervey Welker, Public Administration in the United Skapes, paic. 121.

(11) L. D. White, Introduction to the stualy of Poflic Adrodnintration plez. 53-60. deseravolvimento da análise da chefia enquadrando no sezuinte tópico as fundamenton da eficièn. cia do governo: "a eftciéncia governamental exige - estabelecimento de um Chefe Executivo camo um responsaivel e efetivo centro de energia, direçăo $e$ orzanizaçâo administrativa ; a sistematizsç๊o de tổas as stividades nas mâos de pessoal qualificatio sob a erientaçion do Chefe; e, para auxilia-lo neste proposito, o estabelecimento de aglacias auxiliares", (12)

\section{A EXPERIENCIA INGLESA}

Uma ampla experiéncia administrativa levaria os ingléses a identificarem uma acentuada dife rença entre atividades ciretamente ligedas aos fins colimados pelo govérno e atividades estritamente inatrumentais. Os frutos dessa experiências sutian sistematizacles por um norte-americane, 9 Prol, W F. Willoughby, cuja terminologia, boje, cofrente, qualifica, de fans, funcicnais ou especificas as peimeiras daquelas atividades, e as ios, instifucianais ou ferais as seguadas.

A prática evidenciara sinda, acs ingléses, a grande similitude existente entre as atividades meios, quaisquer que fossem os fins que as mesmas subsidiassem. Os problemas técnicos tle jromoxio de pessoul, compra de material, elaberaçäo orcamentária, ete., eram semelhsntes, quer surgissem num árgầo de educaçăo ou de agricultura.

Duas conclusōes fluiam da identificaçî̉o dềsses problemas : a) as mesmas normas gerais podiam - deviam aer utilizasdas para todes os órgios de aximisistraçăo ceral e a experiência de cada um utilizada a bem de todos; B) os mesmes inatry. mentos de trabalhe e o mesmo pessoal podiam ser empregados na administraçâo geral de tồdas as agências - ou melhor : a administraçăo geral pode, em tese, ser centralizada, disto resultando uma sensivel economia.

Analizando o begño que, em gruade parte, centralizava a administractio geral an Inglaterra o ministério do Tesouro - Willnughby percebeu que easa agéncia estava perfeitamente aparelhada para prestar ao Chefe Executivo aquela assistència essencial ao exercicio de sua funçōo. Irientificava-se, assim, o denominador comum a essa

(12) Report of the President's Commities un Adminintrative Manacement. t937, píg, 3. 
duas espécies de órgî́os - de estado maior e de administreçló auxiliar - que era a funçlĭo de contrỏle sobbre as agèncias operatórias.

\section{A TEORIA DO D.A.G.}

A teoria do Departamento de Administração Geral - formulada por Willoughby - surgiu com a fusỉo, num todo orgìnico, das agèncias de adimipistraçio auxiliar, com o estado maior da cbefia executiva.

Duas análises de mecanismos administrativos, processadas independentemente, - a da chefia executiva $e$ a das atividades de administrachlo geral - constituiram, assim, os pontos de partida fa tecria do D.A.G.

A anâlise da chefia levaria à sua institucionalizaçlio, ou melhor, à constituiçủo de um estado maioe (staff), ou agêneia capaz de ampliar a capucidade do chefe, quer instruindo-0, quer documentando-a, quer verificando a efetivaçăo de suas ordens.

A identificação da similitude entre as ativida. tes meios, levando a centralizaçāo das mesmas e a sua aproximaçäo do chefo executivo, fazia survir para êste um instrumento de contróle ramifica: do em toilos os canais da organização.

Reconhecendo que us atividades de adminis. traçaio geral representavam a melhor base de equipamento do estado maior da chefia, o por outro tado, que o chefe, para efetivar a sua vontade, encentrava nos canais da administraçio geral um magnifico instrumento, idealizou Willoughby uma aplacia que integrasse ambas as atividades, de estada maior e de administraça meio. Denomi. nua-a de Departamento de Administraçãs Geral. (13)

A teoria do D.A.G., resultou, assim, diretamente do reconhecimento da necessidade de criaḉs junto h̀ chefia de agëncias, a um só tempo. de aconsethamento e de adiministraçio geral. Sua

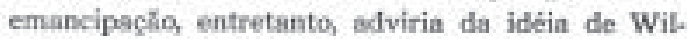
loughby de corporificaçäo, em um todo orgânico, de tôdas as agḱnclas auxiliares da chefia. Surgin ussim a idéia de existència de um só órdaio auxiliar da chefia. $\mathrm{E}$ isto era taื่ mais importante quanto trazia implicito o principio de uma eoorde-

[13) W. F, Willoochby, Pubfic Adminiafratian, 1927, pien, 109. naçắo, descle os niveis inferiores, de tôdas as ativilades auxiliares da chefia, As normas relativas a pessoal, p.ex, eram elaboradas em um Grgaio que tiala igualmente conseiência das problemas te argamento, material, ete, 0 chefe executivo nằ receberia consethos fragmentiluios, fieando-the a responsabilidade de coordenacio dos mesmos. Essa coordenactio em altime estígio pode see inoperante ou lincompleta. A idéia de que begĩos ef organizaçăo, orçamento, material e pessoal, deverestar coocdenadoa desde as primeiras fases do trabalba, está na esslneia da teoria do Departamento de Administraçüo Geral. Trata-se de evitar a tendẻncia as unilateralismo, dos vários órglios em que estiver funcianalizada a chefia.

A primeira experiẻncia, já resultante da nova cocrente de idéias, de instituiçäo de um $D, A, G$., foì, sem đúvida, incompleto, nāo obstante o Departamento de Financas criado no Estado de IItinois em 1917 (14). Desde entĭ́a e particularmente depois da pubticaçio das obras de Waloughby, foram incimerca os árghos desan natureza que surgiram. Encontramo-los, com menor ou maior âmbito de aç̄̄o, sob denominaçốs diversas : Departamento de Financas, de Financas e Controble, de Administraçió, de Administraçlio e Finanças. Persiste nos Estadas Unidos, entretanta, certa relutância em atribuir ao D.A.G., atividades tipicamente institucionais, quais sejam administração de pessoal, consultoria juridica, ete. A existència de várias ageincias de administraçjo geral, ligadas a uma mesma chefis, ainda é comum.

Dois problemas de organizaçác esperam o estudioso logo no pórtico da tearia do D,A.G. O primeiro diz respeito à estruturachăo dessa agência, o segundo se refere à coexistêncin de agências de administraçīo geral, em um mesmo órgāo, ligadas a chefins de niveis diversos.

O primeiro désaes problemas tem levalo à estruturaçâe funcionat do D,A.G, A dificuldade maior trazida por essa forma de estruturaç̆o é a tendencia ao surgimento de departamentoa estanques. Atividades de organizaçlo e orçamento tèm de ser coordenadas em tódas as suas fases. Problemaa de classificaçlo de cargos e de analitse de trabalho - entregues a tícnicos de pessosil e organizaçẫo, respectivamente - săo apenas dois lados de uma mesma coisa. Tem-se reconhecido

(14) A. B. Buck, ob, dit, Dág 22 . 
a necesaidade de uma integragla autêntica dentro do D.A.G., o que năo é fácil conseguir com as estruturas funcionais presentemnete adotadas. A splicaçāo da teoria do D.A.G. muitas vêzes näo tem passerlo da criaçīo de uma cupola fictícia, sob a qual continuam trabalhando, chila uma para um lado, as agências de pessoal, material, orçamento, etc. Este fenòmenos é de cansequências mais graves quando no D.A.G. as atividades de pesquisa $e$ estudo sobrelevam às de rotina.

O segundo problema canfigura-se nas administraçóes de grande vulto. Os grandes departameatos - tais os noseos Ministérioa - possuem chefias altamente complexas que, uma vez institucionalizaclas, dỉo lugar a agếncias da mesma natureza daqueta que foi advezatla para chefia central. Ademais, as atividades de administração geral nāo podem ser totalmente centralizadas em tais essos, pelo simples fato de que ao chefe central níc cabern tốdas as decisóes concernentes às ativilades ligadas a pessoal, material, etc. A admisah́o de determinala categoria de pessoal, p.ex., por ser feita per um chefe de grande departamenta. e năo pelo executivo central, que deve ser desafogodo de detalbes dessa ordem. A conclusaio é que deve haver agencias de administraçio geral em mais de um nivel. A idéia de tigaçâo entre essas ugincias atraves de uma divisio do trabalho entre elas, é a matrix do Sistema de Administraçato Geral. Comumente os órgãco dèsse sistema sŏ articulados através de uma subordinação têcnica dos inferiores aos superiores. Assim, tỏda decislo que afeta a mais de un b́rgăo do mesmo nivel. theve partir de nivel superior.

A teoria do D.A.G., deu lugar, sssim, a dots tipos de sgéncias dessa naturena : a) uma centralizadora de tódas as atividendes institucionais e ligada à chefía central; b) outras articuladas em sistema e distribuidas pelos vilaios aiveis de chefias.

\section{A TEORIA DO D.A.G. NAS OBRAS DE ALGUNS TRATADISTAS}

O Departamento de Administracaso Geral constitue um dos temas centrais dos estudos modernos de organizaçăo administrativa. Um cotejo, mesmo superficial, dêsses estudos, é de interésse para a compreensão do problemn.

\section{a) A5 sugestōus de. wrL.Louchar}

W. $\mathbb{Z}$. Willoughby caracterizando o chefe executivo camo "general manager" do govérno, reputa ser seu dever precipuo exercer contróle keral sōbre as atividades institucionsis, e afirma + "Afim de que fique assegurada a nectssúria uniformidade $e$ o emprego dos métodos mais eficientes á pecessairie que o poder de prescrever c, subecquen. temente, assegurar a exata execuçăo ditsses baveres, seja atribuido a alguma agência que exerça jurisctiçâo geral sóbre todos os serviços. A única agéncia com tal jurisclição é a chefia central. Se esta importante fase da administraçás pública merece wr adequadamente desempenhada, toraa-se dever do chefe executivo, em sua capacidade de gerente geraL, assumir a açäo requerida, a fim de axsegurar que esta classe de atividades seja executala adequadamente. Assim fazenilo, ble tem a considerar $s e$ o fim em vista pode ser melhotmeate atiagido stravés da preacricilo dos métodos a serem seguidos pelos víarioa serviços ou atravís đa criaçāo de agéncias centrais, tal coeno uma agéneia central de compras, de contabilidade, ete., para prestar serviços a todos os demais òtgios", (15)

O ûltimo periodo do trecho transcrito deixa bem claro que Willoughby admite duas formas de orga: nizaçāo das atividades institucionais: a simples coordenação por prescriçăo de normas e a instituich̆o de asêtnciss centrais enearregadas de núclecos especificos do atividades institucionais, tais como compras, coctabilidade, ete. Nío obstante, maí adiante, subindo até a concepclío de um órgĭo geral integrante das atividades institucionais, êle evidenciará a necessidade do "estabelecimento de um serviso de administraç̃o geral, anílogo ìquete do Tesouro no govírno britâtsico, o qual, nūo tendo nenhuma funçlo de administraça especifica, servirá como um órgâo através do qual o chefe executivo possa efetivameate desempenhar suas atribuisoóts de gerente geral"., (16)

Sem descer a mais esclarecedora anallisè dêsse órgāo central, o autor, que argumenta tendo eim vista as necessidades do govêrno federal ameri. cano, discute em segrida a conveniéncia de integraçäo, em nivel ministerial, das atividades institucianais. Diz: Massim camo o chefe executivo

(as) Wninghby, ob. elt., 46.

(16) Willoraghby, ob, cit., 104. 
deve exercer uma supervisilo geral sobre os ministérios, no que deve ser auxiliado por um árgän especial, da meara forma o chefe de cada ministério deve exercer un igual contróle sobbre on várics serviçou que the suio subordinados e, por conse Euinte, ter um ótgïo especial para o auxiliar n:

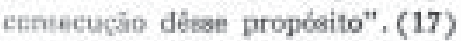

Esses Grgâos de administraçio geral ministeriais deveriam ser chefindos, na opinión désse autor, per elementos da estabilidade e do prestígio admi. nistrativo dos sub-secretários de estado británicos.

Willoughby propole a sequiate estrutura pera os órglos ministerias is de administraça geral ; 1) Serviço din Administraçló: 2) Divishâo de Arq̨uí. vos e Comunicaçōes: 3) Divistio de Pessaal; 4) Diviss̄o de Material; 5) Divisāo de Contabilida. de; 6) Divistio de Publicaçöes. (18)

O gxave problema da articulaçüo to érgâo central com es ministeriais - os nivela de competinsia e as formas de subordinaçito - nâko fol entretanto, esclarecido pelo fecundo autor.

\section{b) A FósMrUt.A RIGIDA DE WALKER}

Se Walloughby raciocina em termos de administraçìo federal, o campo de obeervaçāo do Prof. Harvey Walker purece ser a máquinn administrativa de govirnos locais ou de estados-tnembros smericanos.

O Vúcido anulista de 'Public Administration in the United States", constrói uma teoria de Depar. tamento de Administração Geral partindo dos très seguintes pentos: $a$ ) os objotivos de qualquer governo devem ser clarsmente definidos; b) é imprescindivel a formulaçuo de um plano para consecuçäo désses objetivca ; c) investido da responsabilidade de velar pelo cumprimento dèrse plano, deve haver um grupo de elementos competentes ( (19)

A definiçào de objetivvos é missão do chefe executivo junto as corpo legislativo, Quanto ao preparo dos planos é esta uma tarefa ampla que Walker divide em duas partes 2 a) planos relativos in trabalhos a serem continuados; b) planes relativos a trabulhos nowos. A parte mais com. plexh do preparo dềsses planos deve caber ao

(17) Willoaghby, wh. cit., 104-16.5.

(18) Walloughby, at, cit., 108.

(19) Marvey Wather, ob, eit, Dács. 119 e soguietes. chefe executivo, formulador que \& da politica do gawêrno, po que deve ser assistido por uma equí pe de técricos. Relativamente ao controble da execuçẫo dos planos, cuja últimn responsabilidade cabe ao chefo executivo deve ser feito por elementos de fora dos departamentos executores.

A necessilade de coordenar o trabatho de todos. èsses auxiliares do chefe executivo, seja na formulachio da plano, seja no contrôle de sua efetiva. క̧ēo, pós o Prof. Walker diante da contingència de abordar a teoria do D.A.G. E féslo defendendo pontos de vista positivamente racicais. Assim pretende êle apresentar a organizaçio jedeal sle uma agincia desson natureza partindo do principio da complata centralizaçăo das atividades institucionais. Tal agếncia ahrangeria : planejamento a crganizaçî̀, arçamento, coatabilidade e auditaria, corapras, pessoal, taxaçâo, consultoria juridica, relatórios e possivelmente outras de meoor vulto, (20)

De acúrdo com a maió ou mesar amplitude da máquìna administrativa, maior au menoe seria o D.A.G., sempre deatro do princípio da centra. lizaçio.

Pela análive que fas dos aspectos particulares do problema - as dificuldades decorrentes da completa centralizaçấo contábil, p,ex. - scomos levados a crer que o Prof. Walker limitou as suas pesquiras a pequenas unidades de govérno, E a sua, sem dûvida, uma das formas mais rígidas sab que se tem apresentado a teoria do Departamernto de Administração Geral.

\section{c) a rsourMA DS PFIFFNER}

Outro ilustre tratadista, o Prof. John Pfiffner, aceitando a fórmula de distinço de atividades institucionais e funcianais, aborda u tecria do D. A. G , partindo do reconhecimento da necessidisle de contróle centralizado das primeiras daquelas atividades. (21)

Porque nilo ateve o seu raciocinis aos pantas de referéncia do govèrno federal americano, camo fizera Willoughby, o Prof. Pfiffner, admitindo tam. bérn a necessidade de um órgio central de admi. nistraçalo geral e b́rginos do igual nafureza inte-



(21) Jahn Pfitfer, Pablie Admingraeion, pies 57 a seguintes. 
grantes dos vârios departamentos, pôde dar um maior acabamento à sua teoria. Assim é que propós a articulaçáo de tódas as peças - a central e as departamentais - em um sistemi le relaçies.

A maneira singela como apresenta esta soluçấn ,evidencia que Pfiffner pôs o problema em térmos de administraçăo municipal ou urbana. o que, sliás, vem indicado no desenvolvimento dos coppitules precedentes da mesma obra.

Esse autor aconselha a implantaçás de um D.A.G., imediatamente subordinado ao chefe executivo, bem como a de um órgĩo de igual naturexa em eada uma das grandes unidades operatórias. Ao órgão central caberia a supervisão e đ contrüle das unidades localizadas nos vírica departamentos. "Os membros destas últimas unidades - diz Pfiffner - seriam diretamente responsáveis perante os chefes dos seus departamentos e seriam parte integraste dos respectivos departamentos, mas estariam sujeitos \& sujervisâo * uọ contrỏle do órgão central de administrackỉo em muitos e importantes aspectos". (22)

Neste estágio de sua evolucioio a tecria do Departamento de Administraçăo Geral ingressou na práticu administrativa brasileira.

\section{IMPLANTAÇスO NA ADMINISTRACCAO FEDERAL DO BRASIL.}

\section{AS LENHLAS CERAIS DA REFOFMA}

A refarma administrativa brasileira, iniciada em 1936 e diretamente inspirada na experiència anglo-americana, visou concomitantemente o aparethamento das chefias executivas e a raciomalizaghio das atividades auxiliares. Já en seus primejros passos ê perfeitamente identifichivel todo um plano de agarelhamento da chefia central do goverrno e das chefias de nivel ministerial atraves de um eonjunto de érgãos que, uma vez articuladoa, dariam lugar a um completo Sistema de Administraçî̀o Geral.

Nho se simplificava, entretanto, a reforma, na criacha de agiacias auxiliares des chefias principais - o DASP junto à Presidèncía da Repúbli. ca e os Departameatos de Administração junto às chefies dos Ministerios. Era essencial, ademais,

(22) John Pfifiner, ab, eit-, pág. 59. que se aboedasse o problema da articulaçāo dessas agéncies com a rede de órgâos sôbre que teria de exercer-se sua atividade. Quer para desempenhar funçbies de acoaselhamento junto às chefias executivaz, quer para agir como supervisores des planos de açio dessas chefias, quer ainda para exiecutarem as atividades estritamente ausiliares do rutina, os D.A.G. - o central como os ministeriais - terium de entrar em contato cam uma cadeia de ánzícos espathados pơ uma vasta śreu.

Havia, ainda mais, que considerar a necessidade de aparelhamento das chefias executivas de niveis inferiones dentro dos árgäos de linha. Em raxbio disto surgiram as divisōes, serviços, seçōes e turmas de administração zeral. Analizados es tes mesmos problemas em face da superposiçäo das âreas jurisdicionais das chefias - de ministério, departamento, divisắ, ete. - evidenciarawe a convenilsacia de se articularen 68 unidades de administraçôn gerat, de forma que às de nivel inferier coubesa u realiraçâo de medidas prepa. ratórias is atividades das de nivel superior. Desta forma, em cada Ministério se formou uma cadeia de órgíos auxiliares ligados por um fluxo centripedo de atividades.

A existèncin de uma rede de órgãos articulados em sistema, ou seja realizando fases sucessivas de um mesmo trabalbo, condiciona um outro problema técrico : o urau de centralizacão das atividades, gues de estudios e pesugisas, quer executórias,

No caso brasileriro, acontecia que a exiguidsde de elementoa ticnicamente treinados e a necessidade te imprimir um ritmo inicial unifocme ao trabella das várias pecar do sistema sonselhavam a centralizaçáo dus atividudes normativas no órgầ central - o D.A.S.P. Relativamente ìs atividades de seleçăo de pessoal e compeas de material, ratzổes de ordem técnica a par de uma politica de moralizeção, determinaram uma centralizaça também da parte executória, possibilitadora que era the um mais eficiente contröle. Para as dsmais atividades executórias firmou-je o principio geral de descentralizaçlo per ministério, ou órgiko diretamente subordinado î Presidencia da Repóblica.

\section{A Estretroka no sETEMA}

Um outro problema tecnico que o reformador brasileiro teve de resolver foi o da estruturação do sistema. 
Era preciso conciliar dois principios opostos e de concomitante pressia : a integraçalo de funçbo - orçamento, material, pessoal, etc. - em cada nivel de chefia, e a uniformidade de politica no campo de cada uma dessas fungōes - unidade de direşūo. Ainda aqui se manifestava a dicotomia que estava na essecisis do sistema, posto que car-

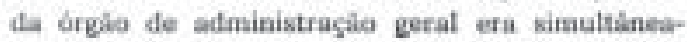
mente um estado-maior da chefia executiva a cujo lado se encontrava $e$ instrumento de traballo de unidades superiores, para as quais tomava medi: dis preliminares de rotina.

A solidez do sistema repousava, portanto, em uma eficiente articulaçä̉o verticat, baseada na diferenciaçăo de funç̧̌̉es - o que condicionava a formaçilo de sistemas distiatos : pessoal, material, orçamento, etc. - e uma perfeita integraçlo des: sas várias funçôes em cada nivel, o que era essencial à formulaçắ da politica e à programeçấo do trabalho em cada nivel de cbefia.

A fórmula que se encontrou para soluça dèste problema cansistiu em conservar as unidades de pesscal, material, orçamento, ete., sob supervisăo unificada - pelo que cada turma, seçấo ou serviço de administraçấ geral seria uma miniatura de D.A.G. - e relacioná-las, do ponto de vista técnico, cocat as unidades de igual funçio em nivel superior. Concomitantemente a direşio técrnica dos vários sistemas funcionais seria unificada em niveis ministerial e nacicanal, obtendo-se una wo orientaç lofo doutrinária para tồda a Administraçăo e uma só politica executóría para cada Ministério.

Sintetizands a evoluçăอ de hdétas qุue temos historiada, podemos resumir nas trla seguintes itens oa fundamentos da reforma que instituiu o Sistema de Administração Geral implantado no Brasil :

2) articulaçắo dos órgh̆os auxiliares das chefias executivas de todos os niveis;

b) centraliraço das atividades de estudos, e descentralizaçāo, como regra, das atividades exocutóriass; c) supervisio unificada das atividades de administraçăo geral a serviço de um mesmo órgăo e articulaçâo funcional entre unidades de niveis stapevpostos, originando sistemas coavergentes.

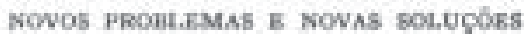

Apòs dez anos de experiència, podemos hoje sfirmar que as solucóes apresentadas para os problemas téeniço fundamentais foram as mais acertadas, se se tem em vista o clima igualments revolucionirio e construtivo em que se desenvolvin a refocma administrativa no Brasil.

Os numerosca problemse marginais que a implantaçũo da reforma traria, iriam capłlictanar uma progressiva transformaçäo do panorama geral. Assim, nāo muits tande teriam de ser reconsideradas as atribuiçōes dos órgâos de administraç̃o geral intra-ministeriais, posto que logo se cvidenciou uma tendência de submersaio dea atribaiçōes díxses érgîas cono estados-maiores das chefias executivas, em beneficio dos trabalbos de rotina administrativa. Igualmente necessário se ria recoensiderar, em face da crescente multiplicaçióo dos problemas administrativos e do anseio geral de progressiva methoria de métodos de trabatho, a centralizaça total das atividades da estudo. Isto por trís motivos principais : a) ja se faziam sentir os efeitos da politica de seleráa e aperfeiçoumento do pesscal e erescia o númera de elementos tècnicamente treinados; b) a melbor maneira de combater aquela tendência para limitaz-ke a trabalbas de rotina seria empregar èsses árgalos de uma fase num plano geral de estudos; c) as atividades de eatuda, em suas fases preí. minares, seriam realizadas com vantagem por órgilics que mantivessem um contacto mais imediate cam cos executores.

A existência dístes problemas foì reconhecida pela recente reforma do órgüo central do Sistema - o D.A.S.P. $\rightarrow$ orientada que foi no sentidc de uma mais ampla descentralizaç̧ă que nâo chegou a cindir o sintema anteriar. 